\title{
SOCIOLOGIA DA PRISÃO
}

\author{
Por Isabel Pojo do Rego*
}

COMBESSIE, Philippe. Sociologie de la prison. Paris: Éditions la Decouverte, 2001. 128 p. (Collection Repères)

O tema da prisão ainda não foi suficientemente tratado no Brasil sob o ângulo metodológico. Não encontramos bibliografia que oriente àqueles que se iniciam neste campo de análise a como fazer um estudo sociológico da prisão. Por isso, gostaríamos de deixar uma contribuição em forma de resenha da obra Sociologie de la Prison, de Philippe Combessie.

Este autor francês dedicou-se a escrever um livro que traz uma síntese das principais abordagens contemporâneas dos cientistas sociais da Europa e Estados Unidos. Este estudo ressalta a diferença entre o olhar sociológico e o olhar jurídico no estudo das instituições prisionais, oferecendo ao leitor uma rica bibliografia comentada.

Combessie é sociólogo francês, vinculado ao Groupe de Recherche et d'Analyse du Social et de la Sociabilité - CNRS IRESCO, e professor na Universidade de Paris V. Sua primeira constatação ao se dedicar ao estudo das prisões foi perceber a dificuldade de se comparar os dados sobre a legislação penal entre os diferentes países, pois o risco de enviesamento é grande. Cada polícia tem procedimento distinto ao informar sobre a detenção. Há países onde a polícia considera a prisão temporária como dado concreto sobre o número de presos, outros não. Por essa razão, ele acredita ser difícil fazer comparações fora de um mesmo país, isto é, entre distintas legislações carcerárias. No entanto, o autor percebe que comparações

* Discente do curso de doutorado em Sociologia na UnB. 
sobre a função social da prisão não só são possíveis, como recomendáveis.

A prisão, como a conhecemos hoje, é um lugar de reclusão onde o indivíduo, acusado por algum tipo de crime, é condenado a cumprir pena privativa de liberdade. A pena de prisão tem sua origem nos ideais humanistas do século XVIII, como mostra o artigo VII da Declaração dos Direitos do homem. Ela surge em substituição à pena de banimento e aos suplícios. No entanto, é importante ter claro que a reclusão não coincide com a pena de prisão. A reclusão foi um instrumento utilizado pelos grupos sociais desde sempre.

No Antigo Regime, Combessie identifica quatro diferentes campos para classificar a reclusão, a saber: 1) o campo jurídico desde a Antigüidade; 2) o campo político para prender os opositores do regime; 3 ) o campo administrativo das cidades que prendiam mendigos e indigentes e, por fim, 4) o campo familiar para retirar do seio familiar as crianças ou jovens que envergonhavam o grupo, como era o caso das meninas que engravidavam antes do casamento. A prisão moderna surge, em parte, sob a idéia de promover trabalhos forçados, afirma o autor.

Além disso, a prisão traz consigo a concepção cristã da penitência, cujo objetivo quase terapêutico é o de submeter o criminoso a condições precárias de vida como forma de pagar o mal que fez à sociedade. É preciso sofrer para reparar as faltas cometidas. Tratar o mal com o mal, salienta Combessie. O autor observa ainda que apesar dos apelos humanistas do século XVIII, a pena de prisão não se constituiu num instrumento de recuperação do indivíduo ou ainda como medida exemplar para coibir novas possibilidades de transgressão.

A questão legal da pena de prisão nem sempre é respeitada. Ainda hoje existem encarceramentos arbitrários em todo o mundo. Combessie sublinha que desde o período da industrialização, no século XIX, a prisão das classes ditas "perigosas" se faz sentir. A elite dirigente e defensora dos ideais democráticos utiliza a pena de prisão para exercer o controle social em momento de grandes conflitos econômicos (Combessie, 2001). 
Nesse sentido, Claude Faugeron (apud Combessie, 2001) identifica que a prisão vem servindo a diferentes lógicas sociais. Ele ressalta principalmente três tipos: o encarceramento com o sentido de neutralização, ou seja, que busca afastar do convívio social o indivíduo verdadeiramente perigoso para a sociedade; o encarceramento no sentido de diferenciação social ou ressocialização, aquele que tem por finalidade proporcionar na cadeia uma formação adequada para que o criminoso possa ser reabilitado a voltar à sociedade; e, por fim, o encarceramento de autoridade, o que visa afirmar uma relação de poder.

Essas lógicas de detenção são aplicadas geralmente em conjunto, prevalecendo sempre uma mais que as outras. A lógica que Faugeron chamou de diferenciação social geralmente não corresponde à realidade, observa Combessie, porque mesmo que as prisões tenham projetos de educação, trabalho etc., visando à reintegração futura, estes são tão tímidos que não chegam a adquirir uma importância de fato no processo de reabilitação da população carcerária.

Por outro lado, as lógicas de detenção apóiam-se nas justificativas das penas. Há dois séculos, a sanção penal vem justificando e legitimando o encarceramento, afirma Combessie. Para Álvaro Pires, em "La formation de la rationalité moderne" (apud Combessie, 2001) existem quatro principais justificativas para a sanção penal:

1) A expiação, adotada também por Kant como "retribuição", pressupõe que ao condenado deve ser imposto o mesmo mal que ele causou. Segundo Durkheim, a pena protege a sociedade porque é expiatória. O criminoso deve reparar o erro que cometeu sendo castigado e submetido à mesma intensidade da dor que provocou.

2) A dissuasão, cujo objetivo é o de prevenir, de demover as pessoas a cometerem algum crime por meio do exemplo do castigo infligido aos condenados. Essa lógica utilitarista, que tem Beccaria como seu principal teórico, está voltada para o futuro, não tem cunho de reparação. O que aqui 
importa é a visibilidade da pena. A sociedade necessita ver as marcas dos corpos que sofrem.

3) A terceira lógica identificada por Pires surgiu no início do século XIX com o sentido de neutralização, isto é, impedir que o criminoso continue a cometer novos crimes, ao menos fora do presídio, porque lá dentro é mais difícil neutralizar a ação do interno. A pena mais eficaz neste caso é a pena de morte, "para neutralizar basta eliminar" (pour neutraliser, il suffit d'eliminer - p. 18).

4) A quarta e última justificativa da sanção penal é a readaptação, reeducação, reinserção, etc. Esta justificativa é a única na teoria utilitarista a não fazer uso da pena de morte.

Na opinião de Combessie, ao fazermos o cruzamento entre as justificações teóricas das sanções e as lógicas de encarceramento, só a da diferenciação social e a de readaptação dos condenados convergem, porque se prendemos alguém é com a intenção de soltálo depois. Assim sendo, a função da prisão deve ser a de recuperação. No entanto só raramente isto acontece, pois, na maioria dos casos a prisão dessocializa ao invés de recuperar.

Antes de abordar os atores precisamente, convém levantar as características espaciais do encarceramento. Três tipos principais de espaço prisional, na França, são por Combessie identificados. O primeiro é a delegacia, que acolhe os presos provisórios. A penitenciária, denominada na França por maison centrale, é o segundo tipo de espaço "destinado ao condenado à pena de reclusão, em regime fechado". Neste caso, dois modelos de penitenciária representam tipos ideais clássicos: o da Pensylvania e o de Auburn, baseados no sistema de isolamento individual do preso.

Além da delegacia e da penitenciária, existem também as modalidades de reclusão que chamamos de prisões-albergues que abrigam presos em regime semi-aberto, nas quais os presos saem para trabalhar de dia e ali retornam para dormir. Ou ainda o livramento condicional, às vezes em forma de prisão domiciliar. 
Outra modalidade de prisão é a casa de correção para menores infratores, verdadeiras prisões. Por fim, devemos citar também como lugar de reclusão os centros psiquiátricos, hoje cada vez mais restritos. $\mathrm{Na}$ França existe ainda uma modalidade de reclusão não encontrada no Brasil, que é o centro de retenção para estrangeiros ilegais.

Nesta perspectiva, como construir o perfil do preso? Quando levantamos as características sociológicas dos presos, é necessário ter em mente diferentes abordagens quantitativas, tais como: a quantificação em valores absolutos das variáveis, a distribuição em valores relativos no seio da população carcerária; os mesmo dados em termos de fluxo de entrada e saída dos presídios; a comparação dos dados de determinada variável e como esta está distribuída na população carcerária e na população não carcerária, esclarece Combessie.

Nesse sentido, o autor sugere sete variáveis importantes para traçar um perfil do presidiário:

1) o sexo é a variável que melhor demonstra as discriminações existentes entre os dois sexos;

2) a idade também é uma variável que retrata situações discriminatórias. A maioria da população carcerária francesa é jovem. No entanto, a tendência é de mudança pois, com o recrudescimento das penas, o condenado ficará cada vez mais tempo preso e com isso a média de idade se altera;

3) o status social é a variável medida pela ocupação profissional que o indivíduo desenvolvia ao ingressar num presídio. Combessie sugere uma análise que cruze os diferentes tipos de penas com a profissão que o indivíduo exercia antes da condenação;

4) o nível escolar;

5) o nível de pobreza - um estudo sociológico realizado por Combessie, Gheorghiu e Bouhedjah (1994) concluiu que $57,7 \%$ dos detidos nas delegacias vivem abaixo do nível 
de pobreza contra $60,9 \%$ dos que cumprem pena nas penitenciárias. Se observamos a sociedade francesa como um todo, apenas $14,5 \%$ se encontrava nesta situação em 1985 ;

6) os laços familiares - a pesquisa do Institut National de la Statistique et des Étude Économiques (INSEE) de 1999, mostra que $43 \%$ dos presos franceses com idade entre $20 \mathrm{e}$ 49 anos declaram ter um cônjuge, contra $66,2 \%$ na população francesa. Cada preso possui uma criança em média, contra 1,3 na população. $10,5 \%$ dos presos desconheciam a profissão paterna contra apenas $4 \%$ da população. Para a maioria deles, isso significa que não conhecem seus pais. Esses critérios somam-se a outros tipos de desfiliação, mas não significam dizer que os internos não tenham laços sociais. Apenas não possuem laços tradicionais, como família e trabalho. Mas, a maioria está inserida em rede de solidariedade informal, precária ou formada por bases de convivência marginais (Combessie, 2001);

7) nacionalidade - importante para estudar a realidade prisional francesa.

Se desejarmos analisar cada uma dessas características é conveniente direcionar a pesquisa para quatro campos diferentes: o presídio; a trajetória do preso ao sair da prisão; as práticas administrativas dos agentes, bem como a legislação e a maneira como ela se constitui. Esses campos são mal estudados porque geralmente se estuda apenas o que acontece no interior dos presídios, quase exclusivamente com os internos, alerta Combessie. A trajetória do preso é muito pouco estudada, pela dificuldade do pesquisador na medida em que um ex-presidiário geralmente não se re-insere num trabalho dito "formal" e nem sempre retorna ao seio familiar. O mais comum é que serrem fileiras com os desempregados. Sem um endereço fixo, o acompanhamento não é possível (Combessie, 2001).

Outra abordagem possível no espectro das prisões é a que se refere ao critério adotado na "escolha" daqueles que serão mandados 
para a prisão. Essa escolha determina o perfil do encarcerado do presídio de cada país ou região. É, segundo Combessie, por meio da análise das políticas penais em relação às práticas prisionais que identificaremos essas escolhas. Por exemplo, os jovens são tratados de forma diferente dos mais velhos; os desempregados dos que trabalham; os homens das mulheres, os alfabetizados dos analfabetos, etc. $\mathrm{O}$ processo legislativo também tem ingerência na construção desses perfis diferenciados. Nesse sentido, podemos notar como determinados segmentos da população exercem pressão sobre o legislativo na construção das leis. Esses grupos conseguem endurecer ou reduzir determinado tipo de pena. Howard Becker definiu esses atores sociais como sendo os "empreendedores da moral" (Combessie, 2001).

Quais são as práticas consideradas criminais que levam o indivíduo à prisão? Que fazem os presos dentro das penitenciárias? O dia-a-dia do interno varia conforme o local de encarceramento? Essas são algumas perguntas importantes que Combessie sugere que façamos.

Complementar a estas abordagens, Combessie identifica que a partir dos anos 1960 a prisão passar a ser analisada também como um objeto de estudo da sociedade que a define, organiza e tolera. Ela deixa de ser vista como um espaço social autônomo. A ligação entre a prisão e a sociedade torna-se um eixo central de análise à medida que a prisão tanto reflete as relações sociais da sociedade onde está inserida quanto essas relações sociais da sociedade produzem seus efeitos na prisão.

Na conclusão, o autor estabelece uma reflexão sobre o modelo prisional e a democracia. Na sua perspectiva, a democracia pressupõe visibilidade, da mesma maneira que a justiça. No entanto a prisão se apresenta como a parte oculta de uma sociedade que se diz democrática. Ele acredita que "se esta obra tivesse apenas um objetivo, seria no sentido de contribuir para proporcionar uma maior visibilidade deste lado sombrio da democracia" (Si cet ouvrage ne devait avoir qu'un seul objectif, ce serait d'oeuvrer dans le sens d'une plus grande visibilité de cette part d'ombre de la démocratie - p.108 tradução livre). 